\title{
Growth and carcass characteristics of cast-for-age Merino ewes fed sorghum-based feedlot diets
}

\author{
M. K. Bowen A,D,E, P. M. Pepper ${ }^{\mathrm{B}}$, E. Patterson ${ }^{\mathrm{A}}$, I. McConnel $^{\mathrm{A}}$ and D. J. Jordan ${ }^{\mathrm{C}}$ \\ ADepartment of Primary Industries and Fisheries, PO Box 519, Longreach, Qld 4730, Australia. \\ ${ }^{B}$ Department of Primary Industries and Fisheries, Locked Mail Bag 4, Moorooka, Qld 4105, Australia. \\ ${ }^{C}$ Department of Primary Industries and Fisheries, PO Box 102, Toowoomba, Qld 4350, Australia. \\ Deresent address: Department of Primary Industries and Fisheries, PO Box 6014, Rockhampton, Qld 4702, Australia. \\ ECorresponding author. Email: maree.bowen@dpi.qld.gov.au
}

\begin{abstract}
Grain feeding low bodyweight, cast-for-age (CFA) sheep from pastoral areas of eastern Australia at the end of the growing season can enable critical carcass weight grades to be achieved and thus yield better economic returns. The aim of this work was to compare growth and carcass characteristics for CFA Merino ewes consuming either simple diets based on whole sorghum grain or commercial feed pellets. The experiment also compared various sources of additional nitrogen $(\mathrm{N})$ for inclusion in sorghum diets and evaluated several introductory regimes. Seventeen ewes were killed initially to provide baseline carcass data and the remaining 301 ewes were gradually introduced to the concentrate diets over 14 days before being fed concentrates and wheaten hay ad libitum for 33 or 68 days. Concentrate treatments were: (i) commercial feed pellets, (ii) sorghum mix (SM; whole sorghum grain, limestone, salt and molasses) + urea and ammonium sulfate (SMU), (iii) SMU + whole cottonseed at $286 \mathrm{~g} / \mathrm{kg}$ of concentrate dry matter (DM), (iv) SM + cottonseed meal at $139 \mathrm{~g} / \mathrm{kg}$ of concentrate DM, (v) SMU + virginiamycin (20 mg/kg of concentrate) for the first 21 days of feeding, and (vi) whole cottonseed gradually replaced by SMU over the first 14 days of feeding.

The target carcass weight of $18 \mathrm{~kg}$ was achieved after only 33 days on feed for the pellets and the SM + cottonseed meal diet. All other whole grain sorghum diets required between 33 and 68 days on feed to achieve the target carcass weight. Concentrates based on whole sorghum grain generally produced significantly $(P<0.05)$ lower carcass weight and fat score than pellets and this may have been linked to the significantly $(P<0.05)$ higher faecal starch concentrations for ewes consuming sorghum-based diets $(270$ v. $72 \mathrm{~g} / \mathrm{kg} \mathrm{DM}$ on day 51 of feeding for sorghum-based diets and pellets, respectively). Source of $\mathrm{N}$ in whole grain sorghum rations and special introductory regimes had no significant $(P>0.05)$ effects on carcass weight or fat score of ewes with the exception of carcass weight for SMU + whole cottonseed being significantly lower than SM + cottonseed meal at day 33 .

Ewes finished on all diets produced acceptable carcasses although muscle $\mathrm{pH}$ was high in all ewe carcasses (average 5.8 and 5.7 at 33 and 68 days, respectively). There were no significant $(P>0.05)$ differences between diets in concentrate $\mathrm{DM}$ intake, rumen fluid $\mathrm{pH}$, meat colour score, fat colour score, eye muscle area, meat $\mathrm{pH}$ or meat temperature.
\end{abstract}

\section{Introduction}

Strong markets for sheep meat relative to the reduction in profits from wool production have increased the need for finishing systems for sheep and improvement in their management. The mutton industry represents $\sim 50 \%$ of sheep meat production in Australia (Meat and Livestock Australia 2005) but is based on the use of surplus sheep from wool and sheep meat industries with little effort traditionally applied to ensuring that these older sheep are suitable for the mutton market (White et al. 2001). The majority of mutton produced from pastoral areas of eastern Australia comes from the turn-off of cast-for-age (CFA) Merino ewes and wethers. These sheep are normally marketed at the end of the growing season when they have low liveweight and carcass weight. Grain feeding CFA sheep provides an opportunity to achieve critical carcass weights ( $>18 \mathrm{~kg}$ ) to meet domestic market specifications and thus allow for improved market returns.

Sorghum grain and protein supplements based on cottonseed are normally readily available in tropical and subtropical areas of Australia but have not been commonly used in sheep feeding systems despite their attractive nutritional composition and price. In cattle, it has been widely documented that sorghum has a lower digestibility of starch compared with winter cereal grains, due largely to the encasement of starch granules in a protective protein matrix inside the hard peripheral endosperm layer of the grain (Rooney and Pflugfelder 1986). In addition, the digestibility of the protein fraction in sorghum grain has been shown to be low and variable (Silano 1977). Although sorghum grain has been widely used as a cattle feed, the use and nutritive value of sorghum grain in sheep feeding systems is not well understood (Beretta and Kirby 2004) and more information is required to allow formulation of suitable finishing diets.

Acidosis can occur when sheep are introduced to a highstarch diet without an adequate or effective introductory period. Despite a range of existing management and intervention strategies, acidosis remains a major health problem in sheep 
feedlots (Kirby et al. 2004). Introduction strategies such as inclusion of antibiotics (e.g. virginiamycin) or step-wise increases in the proportion of high-starch grains in the concentrate may improve physiological adaptation to grain feeding compared with the standard recommendation of step-wise introduction to concentrates incrementing at 50 g/animal.day over 14 days.

The present study compared growth and carcass characteristics for CFA Merino ewes consuming either simple, sorghum-based diets or commercial feed pellets. It also compared various sources of additional nitrogen $(\mathrm{N})$ for inclusion in sorghum diets and evaluated several introductory feeding regimes. A review article including some aspects of this experiment has appeared elsewhere (Bowen et al. 2006).

\section{Materials and methods}

\section{Animal management and experimental design}

In total, 318 7-year-old Merino ewes were used in the experiment. The ewes were shorn $\sim 5$ weeks before feedlot entry. One week before feedlot entry the lambs were weaned and the ewes then offered wheaten hay at $\sim 0.7 \mathrm{~kg} /$ animal.day in the paddock while grazing dry season Mitchell grass pastures (Astrebla spp.) on Rosebank Research Station near Longreach in western Queensland. The ewes were not drenched before feedlot entry as faecal egg counts conducted 1 week before feedlot entry showed no worm eggs were present.

The ewes were allocated to 19 groups based on stratified liveweight, with one group slaughtered to provide baseline carcass data. The 301 ewes allocated to the remaining 18 groups were used in a completely randomised design with six treatment diets and three pens per treatment. After 33 days on feed, half the sheep from each pen were randomly selected after stratification on liveweight and were removed to provide intermediate carcass data. The remaining sheep were slaughtered after 68 days on feed. The experiment was approved by the Department of Primary Industries and Fisheries Animal Ethics Committee.

\section{Treatments and diets}

The ewes were offered wheaten hay ad libitum and one of six concentrate diets also offered ad libitum. The hay was provided in hay racks while concentrate was provided in troughs and fed daily at 0700 hours. Concentrate treatments were: (i) commercial feed pellets (pellets), (ii) sorghum mix (SM; whole sorghum grain, limestone, salt and molasses) + urea and ammonium sulfate (SMU), (iii) SMU + whole cottonseed at $286 \mathrm{~g} / \mathrm{kg}$ concentrate dry matter (DM), (SMU+WC), (iv) SM + cottonseed meal at $139 \mathrm{~g} / \mathrm{kg}$ of concentrate DM (SM+CSM), (v) SMU + virginiamycin $(20 \mathrm{mg} / \mathrm{kg}$ concentrate DM) for the first 21 days of feeding (SMU+V), and (vi) whole cottonseed gradually replaced by SMU over the first 14 days of feeding (WC-SMU). In addition to whole sorghum grain, all the sorghum diets contained limestone, salt and molasses at the rates of 14, 21 and $20 \mathrm{~g} / \mathrm{kg} \mathrm{DM}$, respectively, and were mixed in a conical auger mixer. The sorghum diets were formulated with the intention of being isonitrogenous by varying the amount of urea and ammonium sulfate added to the mix. Concentrated urea and ammonium sulfate solution (1-kg solids in $1.5 \mathrm{~L}$ of water; urea: ammonium sulfate ratio of $4.85: 1)$ was sprayed on to the concentrate mix for all sorghum diets, except $\mathrm{SM}+\mathrm{CSM}$, during mixing, with mixing occurring every 2-3 days. For the SMU $+\mathrm{V}$ treatment, Eskalin 500 powder (Phibro Animal Health, Wentworthville, NSW; $500 \mathrm{~g} / \mathrm{kg}$ virginiamycin) was added and thoroughly mixed through the concentrate just before feeding out each morning. The composition of the commercial feed pellet on an as-fed basis was: $446 \mathrm{~g} / \mathrm{kg}$ sorghum, $150 \mathrm{~g} / \mathrm{kg}$ wheat, $120 \mathrm{~g} / \mathrm{kg}$ palm kernel meal (expeller), $75 \mathrm{~g} / \mathrm{kg}$ molasses, $52 \mathrm{~g} / \mathrm{kg}$ cottonseed meal, $50 \mathrm{~g} / \mathrm{kg}$ millrun, $40 \mathrm{~g} / \mathrm{kg}$ sodium bentonite, $29 \mathrm{~g} / \mathrm{kg}$ limestone, $10 \mathrm{~g} / \mathrm{kg}$ urea, $6 \mathrm{~g} / \mathrm{kg}$ dicalcium phosphate, $6 \mathrm{~g} / \mathrm{kg}$ wheat straw pellets, $5 \mathrm{~g} / \mathrm{kg}$ sodium bicarbonate, $5 \mathrm{~g} / \mathrm{kg}$ salt, $3 \mathrm{~g} / \mathrm{kg}$ ammonium sulfate, $1 \mathrm{~g} / \mathrm{kg}$ Acid buf, $0.1 \mathrm{~g} / \mathrm{kg}$ premix, $0.5 \mathrm{~g} / \mathrm{kg}$ Myco CURB M Dry (organic acid-based mould inhibitor), $0.2 \mathrm{~g} / \mathrm{kg}$ Endox Dry (antioxidant).

For all except the WC-SMU treatment, ewes were introduced to the concentrate diets over 14 days, at a rate of $50 \mathrm{~g} /$ animal.day so that by day 14 the sheep were offered $700 \mathrm{~g}$ /animal.day of concentrate. For the WC-SMU treatment, the composition of the concentrate was altered over the first 14 days so that the SMU component was increased at a rate of $50 \mathrm{~g}$ /animal.day while whole cottonseed was included at $150 \mathrm{~g} /$ animal.day for the first 8 days and then reduced by $25 \mathrm{~g} /$ animal.day over the following 6 days. From day 14 to 18 the quantity of concentrate on offer for all treatment diets was increased gradually until sheep were consuming ad libitum concentrate by day 19 .

\section{Experimental procedures}

For each pen, concentrate intake was recorded daily and a subsample of concentrate residue stored in a refrigerator before chemical analyses. An additional daily subsample of concentrate residue from each pen was bulked into an air-tight container over each 7-day period before weekly DM determination. Each time concentrate diets were mixed, subsamples of each diet and their component feed sources were taken for chemical analyses. The DM content of both the concentrate diets and their component feed sources was determined at fortnightly intervals.

Ewes were weighed once weekly at 1300 hours. Rumen fluid and faecal samples were taken from three randomly selected ewes per pen on days 18 and 51 of feeding. On each occasion, sampling commenced at 1300 hours. On the first occasion, sampling was conducted over $5 \mathrm{~h}$ and $20 \mathrm{~min}$ and on the second occasion, over $4 \mathrm{~h}$ and $45 \mathrm{~min}$. A stomach tube connected to a 60 -mL syringe was used to extract $\sim 120 \mathrm{~mL}$ of rumen fluid per sheep. The $\mathrm{pH}$ of the rumen fluid was determined immediately after collection using a portable $\mathrm{pH}$ meter, it was then strained and concentrated sulfuric acid was added to reduce $\mathrm{pH}$ below 3 . A subsample was placed on ice and later frozen before analysis for ammonia-N concentration. Faecal samples were collected per rectum, placed on ice and later frozen awaiting analysis for starch content.

Prior to slaughter, the ewes were taken off feed and weighed immediately at 1300 hours (liveweight before trucking). After weighing, the ewes were allowed access to water for $1 \mathrm{~h}$ and then were denied access to water before trucking the following morning at 0530 hours. Sheep were slaughtered according to standard abattoir protocol in Miles, Queensland, $~ 1.5-2.0$ days 
after taking them off feed. Hot carcass weight (excluding the kidneys and other internal organs) was recorded. Dressing percentage was calculated as hot carcass weight divided by liveweight before trucking. Fat score (scale 1-5) was determined on the hot carcass at the GR site (located over the 12 th rib, $110 \mathrm{~mm}$ from the mid-line of the carcass). Fat and meat colour, eye muscle perimeter and area and meat $\mathrm{pH}$ and temperature were determined on the chilled carcass on the morning following slaughter. Fat colour (scale 0-9) was determined as the colour of the intermuscular fat lateral to the rib eye (M. longissimus lumborum) and meat colour (scale 1A, $1 \mathrm{~B}, 1 \mathrm{C}, 2-7)$ was determined as the colour of the rib eye muscle. It was assumed that $1 \mathrm{~A}=1,1 \mathrm{~B}=1.333$ and $1 \mathrm{C}=$ 1.666. Fat and meat colour were scored against reference standards in accordance with AUS-MEAT Chiller Assessment Standards for beef cattle. Eye muscle perimeter and area were determined for the rib eye muscle. Meat $\mathrm{pH}$ and temperature were determined using a TPS WP-87 portable $\mathrm{pH}$ meter (TPS, Springwood, Qld) with the probe inserted into the rib eye muscle at the 13th rib.

\section{Analytical procedures}

$\mathrm{DM}$ was determined by drying to a constant weight at $65^{\circ} \mathrm{C}$ in a forced draught oven. Samples were milled to $<1 \mathrm{~mm}$ before chemical analysis. The ash content was determined by heating dry samples in an electric muffle furnace (Thermogravimetric analyser TGA-601, LECO Corporation, St Joseph, MI, USA) at $610^{\circ} \mathrm{C}$ to constant weight under an atmosphere of oxygen. Feed samples were analysed for total $\mathrm{N}$ content by a combustion method (Sweeney 1989) using an Elementar RapidN analyser (Elementar analysensysteme GmbH, Hanau, Germany). Ashfree neutral detergent fibre and ash-free acid detergent fibre content were determined using the Fibretec 2021 Fibrecap system developed by Foss Tecator (Foss Tecator 2002a, 2002b). Crude fibre (CF) was determined by the method of AOAC (1975) adapted for the Fibretec 2021 Fibrecap System by Foss Tecator
(Foss Tecator 2002c). Ether extract (EE), or crude fat, was determined by soxhlet extraction using petroleum ether (boiling range $40-60^{\circ} \mathrm{C}$ ) for $16 \mathrm{~h}$ (Kent-Jones and Amos 1957). The starch content of feeds and faeces was determined by conversion of starch to glucose using a two-step enzyme treatment followed by colourimetric determination with a glucose oxidase/peroxidase reagent. All enzymes and reagents were supplied in kit form from Megazyme available from Deltagen Australia (Boronia, Vic.). The enzymatic breakdown of the starch using a heat stable $\alpha$-amylase and amyloglucosidase is based on the procedure of McCleary et al. (1992). Prior to determination of rumen ammonia-N concentration, rumen fluid was shaken and then centrifuged (2600 $\mathrm{g}$ for $12 \mathrm{~min}$ ) to obtain a clear supernatant. After a reaction, which converts ammonia to form an indophenol dye (Bolleter et al. 1961), spectrophotometric determination was conducted on an Olympus AU400 clinical analyser (Olypus, Mount Waverley, Vic.).

\section{Calculations}

The metabolisable energy (ME) content of wheaten hay was predicted using Eqn 67 (Anon. 1975) with a correction for ash content:

$$
\begin{gathered}
\mathrm{ME}(\mathrm{MJ} / \mathrm{kg} \mathrm{DM})=13.5-[0.015 \text { acid detergent fibre }(\mathrm{ADF}) \\
+0.015 \mathrm{ash}]+0.014 \text { crude protein }(\mathrm{CP})
\end{gathered}
$$

where all analyses are in $\mathrm{g} / \mathrm{kg} \mathrm{DM}$.

The ME content of sorghum grain, whole cottonseed, cottonseed meal and the concentrate diets was predicted using Eqn 75 (Anon. 1975):

$$
\begin{aligned}
\mathrm{ME}(\mathrm{MJ} / \mathrm{kg} \mathrm{DM})= & 0.012 \mathrm{CP}+0.031 \mathrm{EE}+0.005 \mathrm{CF} \\
& +0.014 \mathrm{NFE}
\end{aligned}
$$

where NFE (nitrogen free extract $)=1000-(\mathrm{CP}+\mathrm{EE}+\mathrm{CF}+$ ash), and all analyses are in $\mathrm{g} / \mathrm{kg} \mathrm{DM}$.

The $\mathrm{CP}$ content in the concentrate actually consumed (i.e. taking into account the different $\mathrm{CP}$ concentrations in the

Table 1. Dry matter (DM) content (g/kg, as fed), predicted metabolisable energy (ME, MJ/kg DM) and concentration (g/kg DM) of crude protein (CP), organic matter (OM), neutral detergent fibre (NDF), acid detergent fibre (ADF), crude fibre

\begin{tabular}{|c|c|c|c|c|c|c|c|c|c|}
\hline & $\mathrm{DM}$ & ME & $\mathrm{CP}$ & $\mathrm{OM}$ & NDF & $\mathrm{ADF}$ & $\mathrm{CF}$ & Starch & $\mathrm{EE}$ \\
\hline \multicolumn{10}{|l|}{ Feed ingredients } \\
\hline Wheaten hay & 974 & 8.9 & 109 & 906 & 517 & 313 & - & - & - \\
\hline Sorghum grain & 894 & 13.8 & 98 & 987 & - & - & 23 & 695 & 25 \\
\hline Whole cottonseed & 957 & 14.6 & 235 & 955 & - & - & 234 & - & 226 \\
\hline Cottonseed meal & 931 & 11.5 & 518 & 926 & - & - & 97 & - & 25 \\
\hline Molasses & 765 & - & 84 & 879 & - & - & - & - & - \\
\hline \multicolumn{10}{|l|}{ Concentrate offered } \\
\hline Pellets & 921 & 12.3 & 175 & 894 & - & - & 29 & 483 & 26 \\
\hline SMU, SMU+V, WC-SMU & 900 & 13.3 & 138 & 953 & - & - & 25 & 667 & 30 \\
\hline SMU+WC & 921 & 13.5 & 144 & 935 & - & & 77 & 490 & 84 \\
\hline $\mathrm{SM}+\mathrm{CSM}$ & 893 & 13.2 & 148 & 950 & - & - & 37 & 570 & 29 \\
\hline \multicolumn{10}{|l|}{ Concentrate consumed } \\
\hline SMU, SMU+V, WC-SMU & - & $13.0 \pm 0.04$ & $138 \pm 0.6$ & - & - & - & - & - & - \\
\hline SMU+WC & - & $13.1 \pm 0.08$ & $136 \pm 1.1$ & - & - & - & - & - & - \\
\hline $\mathrm{SM}+\mathrm{CSM}$ & - & $13.6 \pm 0.02$ & $125 \pm 5.7$ & - & - & - & - & - & - \\
\hline
\end{tabular}
(CF), starch and ether extract (EE) in feed ingredients, the concentrate diets offered and that actually consumed by ewes (mean \pm s.e.) after day 14

Treatment descriptions are given in the text 
Table 2. Concentrate intake, liveweight and carcass weight changes and dressing percentage for the baseline slaughter (BS) group and for ewes consuming six treatment diets

Treatment descriptions are given in the text. Values within rows followed by different letters are significantly different at $P=0.05$. Feedlot mean and BS group values followed by different uppercase letters are significantly different at $P=0.05$

\begin{tabular}{|c|c|c|c|c|c|c|c|c|c|c|}
\hline & \multicolumn{7}{|c|}{ Feedlot treatment } & \multirow{2}{*}{$\begin{array}{l}\text { Overall } \\
\text { feedlot } \\
\text { mean }\end{array}$} & \multicolumn{2}{|c|}{ BS and feedlot comparisons } \\
\hline & Pellets & SMU & $\mathrm{SMU}+\mathrm{WC}$ & $\mathrm{SM}+\mathrm{CSM}$ & $\mathrm{SMU}+\mathrm{V}$ & WC-SMU & $\begin{array}{l}\text { Average } \\
\text { s.e.d. }\end{array}$ & & $\begin{array}{c}\text { BS } v \\
\text { feedlot }\end{array}$ & $\begin{array}{c}\text { BS } v \\
\text { feedlot s.e.d. }\end{array}$ \\
\hline $\begin{array}{l}\text { Concentrate intake days 19-68 } \\
\text { (g dry matter/animal.day) }\end{array}$ & 1008 & 904 & 843 & 1036 & 929 & 929 & 90.4 & 941 & & \\
\hline \multicolumn{11}{|l|}{ Liveweight (kg) } \\
\hline BS group & & & & & & & & & $40.6 \mathrm{~A}$ & \\
\hline 0 days & 40.4 & 40.6 & 40.3 & 40.9 & 40.3 & 41.1 & 0.49 & 40.6 & A & 0.61 \\
\hline \multicolumn{11}{|l|}{$\begin{array}{l}\text { Liveweight change } \\
\qquad(\mathrm{g} / \text { animal.day })^{\mathrm{A}}\end{array}$} \\
\hline $0-33$ days & 262 & 212 & 256 & 221 & 170 & 201 & 28.5 & 220 & & \\
\hline 0-68 days & 153 & 117 & 135 & 124 & 119 & 115 & 16.9 & 127 & & \\
\hline \multicolumn{11}{|l|}{ Carcass weight (kg) } \\
\hline BS group & & & & & & & & & $16.4 \mathrm{~A}$ & \\
\hline 33 days & $38.6 \mathrm{a}$ & $37.3 b$ & $35.8 \mathrm{c}$ & $37.8 \mathrm{ab}$ & $37.7 \mathrm{ab}$ & $37.5 \mathrm{ab}$ & 0.53 & 37.5 & $\mathrm{~B}$ & 0.67 \\
\hline 68 days & $41.6 \mathrm{a}$ & $40.3 b$ & $40.2 b$ & $39.9 \mathrm{~b}$ & $40.3 b$ & $39.4 \mathrm{~b}$ & 0.51 & 40.3 & $\mathrm{~A}$ & 0.64 \\
\hline
\end{tabular}

${ }^{A}$ Change in liveweight was determined from start and end weights only; note that the actual pattern of liveweight change was not linear.

concentrate offered $v$. that refused) was calculated for each pen as:

$\mathrm{CP}$ content $(\mathrm{g} / \mathrm{kg} \mathrm{DM})=[(\mathrm{CP}$ in concentrate offered $(\mathrm{g} /$ day $)$

$-\mathrm{CP}$ in concentrate refused $(\mathrm{g} /$ day $)] /$ actual concentrate intake $(\mathrm{kg} / \mathrm{day})$.

A similar calculation was used to determine ME content of the concentrate consumed $(\mathrm{MJ} / \mathrm{kg} \mathrm{DM})$.

\section{Statistical analyses}

The statistical package, GENSTAT for Windows, 8th edition (GENSTAT Committee 2005), was used for all statistical analyses. The data were subjected to ANOVA in a completely randomised design with the pen as the experimental unit. Pairwise differences between means were tested using a protected 1.s.d. procedure $(P=0.05)$. Where data were available for the baseline slaughter group, the data were analysed as a completely randomised design with an unreplicated control, the variation between pens in the feedlot being used to test for significant differences between feedlot groups and the baseline slaughter group. The data at 33 and 68 days of feeding were analysed separately and the combined data analysed as a split-plot with time as the subplot factor. Differences in fat colour score were tested using a chi-square test.

Liveweight data were analysed by the residual maximum likelihood method using a random coefficient model with fixed effects (treatment + treatment $\times\left(\right.$ days + days $\left.^{2}\right)$ to allow for separate quadratic profiles over time for each treatment and random terms (pen and pen $\times$ days) to allow for a random intercept and a random slope for each pen. The model was fitted

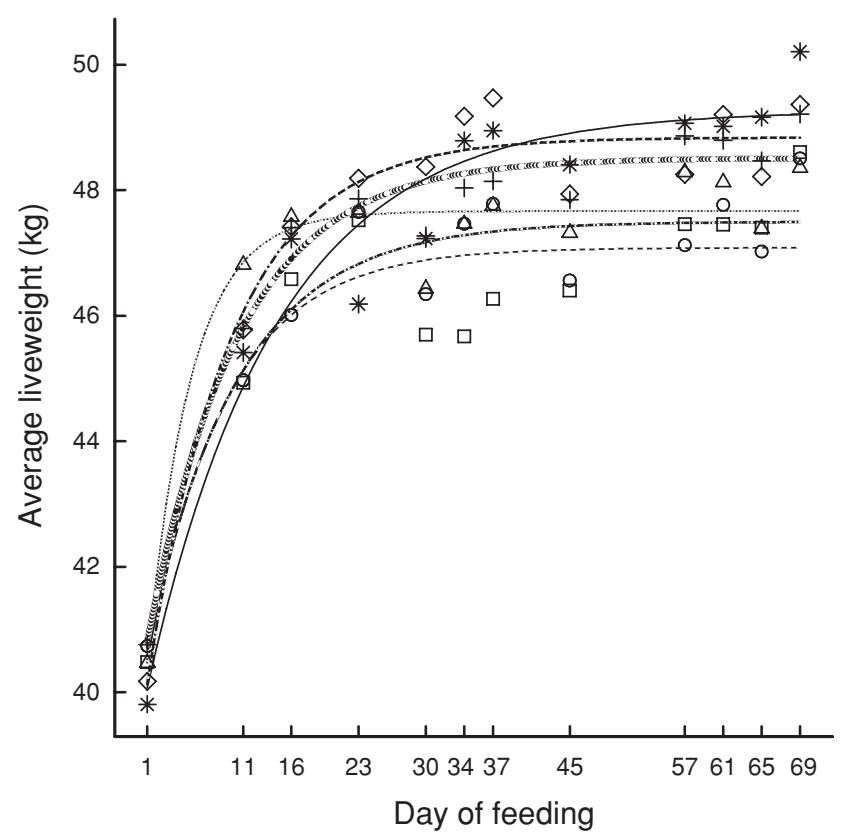

Fig. 1. Change in ewe mean liveweight over the feedlot period. Feeding treatments are: pellets $(*), \operatorname{SMU}(\triangle), \operatorname{SMU}+\mathrm{WC}(\diamond), \mathrm{SM}+\mathrm{CSM}(+)$, SMU $+\mathrm{V}(\square)$ and WC-SMU $(\bigcirc)$. The fitted curves are: pellets, $y=49.3-$ 9.90( $\left(\mathrm{e}^{-0.074 x}\right)$; SMU, $y=47.7-8.96\left(\mathrm{e}^{-0.218 x}\right)$; SMU+WC, $y=48.8-$

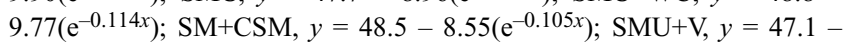
$7.42\left(\mathrm{e}^{-0.121 x}\right)$; and WC-SMU, $y=47.5-7.54\left(\mathrm{e}^{-0.105 x}\right)$. The overall standard error of observations is 0.681 (adjusted $r^{2}=0.91$ ). Treatment descriptions are given in the text. 
with correlation between intercept and slope. Exponential curves were also fitted to the mean liveweights of treatments $\left[y=a+b\left(\mathrm{e}^{-k x}\right)\right]$.

\section{Results}

The chemical composition of feed ingredients and the concentrate diets offered during the post-introductory period as well as the ME and $\mathrm{CP}$ content of the concentrate actually consumed by the ewes is given in Table 1 . The ewes consumed both the hay and concentrate components of the diet very readily during the introduction period, and ate all concentrate that was offered. Once the ewes were consuming concentrate ad libitum (by day 19), large day-to-day fluctuations in concentrate intake occurred. There was no effect of treatment on concentrate intake during the period of ad libitum feeding, with an average intake of $941 \mathrm{~g} \mathrm{DM}$ /animal.day (Table 2).

In the analysis of liveweight data, the Wald statistics from the random coefficient model showed no significant difference between treatments $(P=0.264)$, treatment $\times$ days $(P=0.089)$ or treatment $\times$ days $^{2}(P=0.153)$. Fitting exponential curves to the treatment means (Fig. 1) showed significant $(P<0.001)$ differences between the asymptotes of the curves. Further investigation showed no significant difference between the asymptotes of the curves for pellets, $\mathrm{SMU}+\mathrm{WC}$ and $\mathrm{SM}+\mathrm{CSM}$ or between the asymptotes of the curves for SMU+V and WC-SMU, but the curves, including the asymptotes, for these two groups were different from each other and that for SMU. There were no significant differences between treatments for liveweight at day 33 or 68 or for liveweight change (Table 2).

Carcass weight increased $(P<0.05)$ with day of feeding (Table 2). The carcass weight of ewes fed pellets was greater $(P<0.05)$ than for all whole grain sorghum treatment diets except $\mathrm{SM}+\mathrm{CSM}$ after 33 days on feed and greater than for all except SMU+WC after 68 days on feed. Ewes consuming the pellets diet had greater $(P<0.05)$ dressing percentage than ewes consuming SMU and SMU+WC after 33 days on feed and had a greater dressing percentage than ewes consuming all whole grain sorghum treatment diets after 68 days on feed. After 33 days on feed, the $\mathrm{SM}+\mathrm{CSM}$ diet resulted in a greater $(P<0.05)$ carcass weight than the SMU+WC diet but not than the SMU diet. However, there was no effect $(P>0.05)$ of $\mathrm{N}$ source in whole grain sorghum diets on carcass weight after 68 days on feed. A similar trend was observed for effect of $\mathrm{N}$ source on dressing percentage. Introductory regimes SMU+V and WC-SMU did not increase $(P>0.05)$ carcass weight or dressing percentage after 33 or 68 days on feed compared with the SMU treatment, which had the standard introductory regime.

Fat score increased $(P<0.05)$ with day of feeding, (Table 3$)$. The pellets diet resulted in a greater $(P<0.05)$ fat score in ewes fed for 68 days than for all whole grain sorghum diets except the SMU+WC diet, although there were no treatment differences after 33 days on feed. There was no effect $(P>0.05)$ on fat score of $\mathrm{N}$ source in whole grain sorghum diets, or of introductory regime. Ewes fed the pellets diet had greater $(P<0.05)$ eye muscle perimeter after 68 days on feed than for ewes fed whole

Table 3. Carcass characteristics of the baseline slaughter (BS) group and of ewes consuming six treatment diets

Treatment descriptions are given in the text. Values within rows followed by different letters are significantly different at $P=0.05$. Feedlot mean and baseline slaughter group values followed by different uppercase letters are significantly different at $P=0.05$

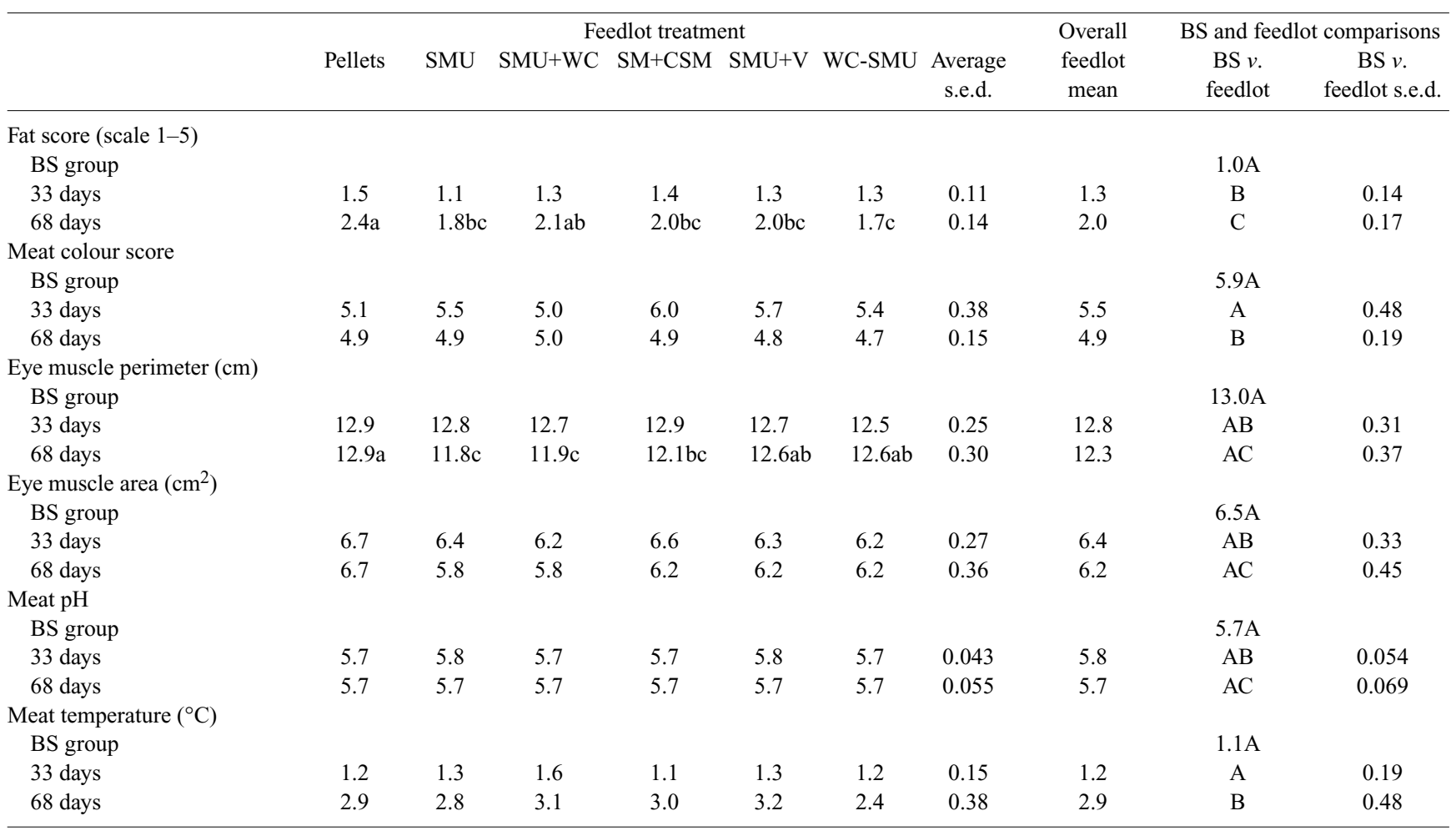


Table 4. Effect of treatment diet on $\mathrm{pH}$ and ammonia $\mathrm{N}\left(\mathrm{NH}_{3}-\mathrm{N}\right)$ concentration in rumen fluid and on starch concentration in faeces for ewes consuming six treatment diets

Treatment descriptions are given in the text. Values within rows followed by different letters are significantly different at $P=0.05$

\begin{tabular}{|c|c|c|c|c|c|c|c|c|}
\hline & \multicolumn{7}{|c|}{ Feedlot treatment } & \multirow{2}{*}{$\begin{array}{c}\text { Overall feedlot } \\
\text { mean }\end{array}$} \\
\hline & Pellets & SMU & SMU+WC & $\mathrm{SM}+\mathrm{CSM}$ & SMU+V & WC-SMU & Average s.e.d. & \\
\hline \multicolumn{9}{|c|}{ Rumen fluid $\mathrm{pH}$} \\
\hline Day 18 & 6.08 & 6.25 & 6.39 & 6.25 & 6.22 & 6.24 & 0.184 & 6.24 \\
\hline Day 51 & 6.58 & 5.90 & 6.24 & 6.11 & 6.32 & 6.08 & 0.202 & 6.21 \\
\hline \multicolumn{9}{|c|}{ Rumen $\mathrm{NH}_{3}-\mathrm{N}(\mathrm{mg} / \mathrm{L})$} \\
\hline Day 18 & $353.6 \mathrm{a}$ & $218.9 \mathrm{~b}$ & $236.3 \mathrm{ab}$ & $175.9 \mathrm{~b}$ & $342.8 \mathrm{a}$ & $173.0 \mathrm{~b}$ & 55.03 & 250.1 \\
\hline Day 51 & 188.1 & 229.4 & 105.2 & 138.9 & 141.2 & 108.0 & 46.85 & 151.8 \\
\hline \multicolumn{9}{|c|}{ Faecal starch (g/kg dry matter) } \\
\hline Day 18 & $50 \mathrm{c}$ & $219 \mathrm{ab}$ & $142 \mathrm{bc}$ & $285 \mathrm{a}$ & $215 \mathrm{ab}$ & $208 \mathrm{ab}$ & 64.3 & 187 \\
\hline Day 51 & $72 b$ & $274 a$ & $239 a$ & $310 \mathrm{a}$ & $248 \mathrm{a}$ & $273 a$ & 58.7 & 236 \\
\hline
\end{tabular}

grain sorghum diets with the standard introductory regime. There was no effect $(P>0.05)$ of $\mathrm{N}$ source in whole grain sorghum diets on eye muscle perimeter but introductory regimes $\mathrm{SMU}+\mathrm{V}$ and WCS-SMU resulted in significantly greater eye muscle perimeter after 68 days on feed than for SMU. Treatments had no effect $(P>0.05)$ on meat colour score, eye muscle area, meat $\mathrm{pH}$ or meat temperature. Fat depth was too small to allow an accurate reading of fat colour in 16 of 17 animals in the baseline slaughter group and in 105 of the 151 animals slaughtered at 33 days. All carcasses with visible fat colour in the baseline slaughter group and at 33 days had a colour score of 1 . Animals slaughtered at 68 days had colour scores of only 0 (112 carcasses) and 1 (38 carcasses). Treatment did not have an effect on fat colour score $\left(\chi^{2}=1.43\right.$; d.f. $\left.=5 ; P=0.92\right)$.

There were no treatment effects $(P>0.05)$ on rumen fluid $\mathrm{pH}$ or on rumen ammonia-N concentrations on day 51 of feeding (Table 4). However, on day 18 of feeding, ewes consuming the pellets diet had greater $(P<0.05)$ rumen ammonia-N concentrations than for ewes consuming SMU, SM+CSM and WC-SMU diets. There was no effect $(P>0.05)$ of source of $\mathrm{N}$ on rumen ammonia-N concentrations but the introductory regime $\mathrm{SMU}+\mathrm{V}$ resulted in a greater rumen ammonia-N concentration on day 18 of feeding than the SMU diet, which had the standard introductory regime. Faecal starch concentrations were significantly $(P<0.05)$ lower in sheep consuming the pellets diet than for all whole grain sorghum diets on both day 18 and 51 of feeding, excepting the SMU+WC diet on day 18 . There was considerable variation in faecal starch concentration between the three animals sampled within each pen, as indicated by a high mean square for animals within pens (13655) for the faecal starch ANOVA at 51 days, although this was less than the residual mean square (15529).

\section{Discussion}

The comparison of simple, sorghum-based diets with commercial feed pellets, the examination of various sources of additional $\mathrm{N}$ for inclusion in sorghum diets and the evaluation of several introductory feeding regimes were conducted in this study under practical feeding conditions to reflect current industry practice. Under these conditions, concentrate diets based on either whole grain sorghum or on pellets were successful in supporting an increase in carcass weight of CFA Merino ewes to in excess of the threshold value of $18 \mathrm{~kg}$, which is commonly preferred for the domestic market (White et al. 2001). In this study, the $18-\mathrm{kg}$ target carcass weight was achieved after only 33 days on feed for the pellets and SM+CSM concentrate diets. All other whole grain, sorghum-based diets required between 33 and 68 days in the feedlot to achieve the target carcass weight.

Concentrates based on whole grain sorghum were generally not as effective as the pellets diet in achieving carcass weight gain and this may have been linked to the significantly higher faecal starch concentrations for ewes consuming whole grain sorghum-based diets. Numerous reports corroborate the lower feeding value of sorghum compared with winter cereal grains or corn, for example Saba et al. (1964) showed that cattle used rolled barley more efficiently than rolled sorghum when fed under comparable conditions. Processing methods such as steam-flaking and reconstitution have been effective in raising sorghum digestibility in cattle to near that of corn (Rooney and Pflugfelder 1986; Theurer et al. 1999) and the pelleting process may have had similar benefits in this experiment (pellets contained $446 \mathrm{~g} / \mathrm{kg}$ sorghum). The high faecal starch concentrations measured in this study for sheep imply that the actual ME values of whole sorghum grain are less than those calculated from laboratory feed-test values with implications for ration formulation and prediction of growth rates. However, the trend towards greater carcass weights for ewes consuming pellets in our experiment may have also been influenced by a greater supply of CP, with the CP of pellets being $175 \mathrm{~g} / \mathrm{kg} \mathrm{DM}$ v. $125-138 \mathrm{~g} \mathrm{CP} / \mathrm{kg} \mathrm{DM}$ in the whole grain, sorghum-based diets actually consumed by ewes.

Liveweight change was a poor indicator of carcass weight change in this experiment. As indicated in Fig. 1, sheep liveweight appears to have reached plateau very quickly after the start of feeding, with little apparent gain for much of the later period. However, the carcass weight data indicates that there was actually a similar increase in carcass weight between days $33-68(1.8 \mathrm{~kg})$ as between days $0-33(1.5 \mathrm{~kg})$. A large increase in liveweight was observed in the first 11 days in the feedlot and was probably due to increased gut fill after feedlot entry, rather than to a corresponding increase in carcass weight. As the sheep were weighed at the same time of day on each occasion, and thus would be expected to have constant gut fill once in the feedlot, the poor correlation of liveweight change with carcass weight change after day 11 of feeding appears to be 
related to dressing percentage effects. In particular, the lack of apparent increase in liveweight in the later period of feeding is probably due to increasing dressing percentage due to increasing fatness over time, similar to results found by others for sheep (Foot and Greenhalgh 1970) and cattle (Wythes and Ramsay 1981; Gulbransen 1990). As trends in mean treatment liveweight were similar to those for carcass weight, the large between-pen variability in the proportion of hay and grain selected in the diet, as indicated by the within-treatment variation in faecal starch levels, could have precluded detection of significant treatment effects for final liveweights. Significant differences between asymptotes of the exponential curves fitted to mean treatment liveweight over time indicate the benefit of pellets, SMU+WC and SM+CSM over the other treatments.

Growth rates of CFA Merino wethers fed a similar whole grain sorghum concentrate diet with added non-protein $\mathrm{N}$ over 42 days $(150 \mathrm{~g} /$ day; Bowen et al. 2006) or 92 days ( $140 \mathrm{~g} /$ day; Bowen et al. 2006) were lower than growth rates of CFA Merino ewes fed SMU in our experiment over 33 days ( $212 \mathrm{~g} /$ day), but higher than growth rates measured in our experiment over 68 days (117 g/day). Similar growth rates, within this range, were obtained for CFA Merino wethers consuming either whole barley with non-protein $\mathrm{N}$ or commercial feed pellets over 42 days (150 and $170 \mathrm{~g} /$ day, respectively; Bowen et al. 2006). These results for CFA Merino sheep were also within the range of indicative growth rates expected for Merino lambs (110-200 g/day; Bell et al. 2003). Starting and final carcass weights were not available for the experiments described above, precluding comparisons of carcass weight gain. Due to the poor correlation of liveweight change with carcass weight change in this experiment with older sheep, and the non-linear pattern of liveweight change, these estimates and comparisons of liveweight change should be treated with caution.

Substituting sources of true protein (cottonseed meal or whole cottonseed) for non-protein $\mathrm{N}$ sources (urea and ammonium sulfate) did not significantly affect the carcass weights of CFA ewes in this study. These results could reflect selection against whole cottonseed and cottonseed meal components of the diet and thus lower than intended CP content in the concentrate actually consumed, particularly for the $\mathrm{SM}+\mathrm{CSM}$ diet, which was 13 and $11 \mathrm{~g} \mathrm{CP} / \mathrm{kg}$ DM less than for the SMU and SMU+WC diets, respectively. The large betweenpen variability may have also precluded attainment of significant differences. Our results are in contrast to those for crossbred lambs, where lambs fed cereal grain with lupins and expeller canola meal had significantly higher growth rates than lambs fed an isonitrogenous diet of grain and urea (Wiese et al. 2003). However, the poor performance of the urea diet in the experiment with lambs was attributed to acidosis associated with a lower concentration of effective fibre in the urea diet, rather than to provision of true protein per se.

Ewes consuming all treatment diets appeared to adapt to concentrates equally well over the 14-day introductory period as no ewes had to be culled due to illness or loss of liveweight. This observation corroborates the finding that special introductory regimes of adding virginiamycin for the first 21 days of feeding (SMU+V) or changing the composition of the concentrate from a high proportion of low-starch grains (whole cottonseed) to high-starch grains (sorghum) over the initial 14 days
(WC-SMU) did not improve growth rates or final carcass weights compared with the conventional introduction strategy of gradually increasing the amount of concentrate offered by $50 \mathrm{~g} /$ animal.day over 14 days. The lack of treatment differences in rumen fluid $\mathrm{pH}$ measured $6-11 \mathrm{~h}$ after feeding provides further evidence that the alternative introductory regimes tested here provided no advantage over the conventional regime. The lower rate and extent of rumen fermentation of starch from sorghum compared with starch from winter cereal grains such as wheat and barley (Bird et al. 1999) imply that the risk of acidosis and related metabolic disorders would be less when sorghum is used. It is possible that different responses to the introductory regimes investigated in this study may be observed when less 'safe' grains are fed.

Carcass quality attributes were generally not affected by treatment in most cases. The exception was for fat score and eye muscle perimeter where the pellets diet generally produced higher values than for other diets, in keeping with the trend for carcass weight. As expected, grain feeding tended to decrease meat and fat colour score over time. Average meat $\mathrm{pH}$ at all slaughter times in our experiment was at the limits of the desirable range of 5.8 or less, with meat above this range tending to be tougher, darker and to have a reduced shelf life (Egan and Shay 1988; Purchas and Aungsupakorn 1993). The high meat $\mathrm{pH}$ values measured in our experiment (5.7-5.8) are similar to those determined by Hopkins et al. (2005a) for Merino wether hoggets (5.76-5.90), with values greatest for finer wool bloodlines. These authors found that the high $\mathrm{pH}$ of Merino hogget meat was related to lowered aerobic metabolism in the muscle which may be a reflection of a change in fibre type frequency. Regardless of the cause of lowered aerobic muscle metabolism, Hopkins et al. (2005b) concluded that an increased likelihood of high ultimate $\mathrm{pH}$ in meat from Merino lambs in their experiment was due to a greater effect of pre-slaughter stress in this breed of sheep, highlighting the need for strategies to reduce the cause of pre-slaughter stress and its impact.

In conclusion, this experiment has demonstrated that concentrates based on sorghum grain provide a basis for a finishing system for CFA Merino sheep for existing markets.

\section{Acknowledgements}

This study was funded by the Australian Sheep Industry Cooperative Research Centre with in-kind contributions from the Department of Primary Industries and Fisheries, Queensland (DPI\&F). We are grateful to the Health and Nutritional Biochemistry Laboratory of DPI\&F for conducting laboratory analyses and to A. Slacksmith of the University of New England for conducting carcass measurements.

\section{References}

Anon. (1975) Energy allowances and feeding systems for ruminants. Technical Bulletin 33. Ministry of Agriculture, Fisheries and Food, London.

AOAC (1975) 'Official methods of analysis.' (Association of Official Analytical Chemists: Washington DC)

Bell AK, Shands CG, Hegarty RS (2003) 'Grain finishing of lambs.' (Meat and Livestock Australia: North Sydney)

Beretta V, Kirby RM (2004) Nutritional characteristics of cereal grains. In 'Feeding grain for sheep meat production'. (Ed. HM Chapman) pp. 33-39. (Chief Executive Officer of the Australian Sheep Industry CRC: Bentley) 
Bird SH, Rowe JB, Choct M, Stachiw S, Tyler P, Thompson RD (1999) In vitro fermentation of grain and enzymatic digestion of cereal starch. Recent Advances in Animal Nutrition in Australia 12, 53-61.

Bolleter WT, Bushman CJ, Tidwell PW (1961) Spectrophotometric determination of ammonia as indophenol. Analytical Chemistry 33, 592. doi:10.1021/ac60172a034

Bowen MK, Ryan MP, Jordan DJ, Beretta V, Kirby RM, Stockman C, McIntyre BL, Rowe JB (2006) Improving sheep feedlot management International Journal of Sheep and Wool Science 54, 27-34.

Egan AF, Shay BJ (1988) Long-term storage of chilled fresh meats. In 'Proceedings of the 34th international congress of meat science and technology. Brisbane, Queensland'. pp. 476-481.

Foot JZ, Greenhalgh JFD (1970) A note on the relation between weights of alimentary tract contents, body fat and the uterus in blackface ewes. Animal Production 12, 669-671.

Foss Tecator (2002a) Application sub-note ASN 3805. The determination of neutral detergent fibre using the Fibercap system. FOSS TECATOR, Hoganas, Sweden.

Foss Tecator (2002b) Application sub-note ASN 3804. The determination of acid detergent fibre using the Fibercap system. FOSS TECATOR, Hoganas, Sweden.

Foss Tecator (2002c) Application sub-note ASN 3801. The determination of crude fibre in feed according to AOAC, ISO, AACC and AOCS standards using the Fibercap system. FOSS TECATOR, Hoganas, Sweden.

Genstat Committee (2005) 'The guide to Genstat Part 2: statistics.' (VSN International Ltd: Oxford)

Gulbransen B (1990) Using supplementary grain to increase the marketability of culled cows. Proceedings of the Australian Society of Animal Production 18, 228-231.

Hopkins DL, Hatcher S, Pethick DW, Thornberry KJ (2005a) Carcass traits, meat quality and muscle enzyme activity in strains of Merino wether hoggets. Australian Journal of Experimental Agriculture 45, 1225-1230. doi:10.1071/EA04219

Hopkins DL, Walker PJ, Thompson JM, Pethick DW (2005b) Effect of sheep type on meat and eating quality of sheep meat. Australian Journal of Experimental Agriculture 45, 499-507. doi:10.1071/EA03176

Kent-Jones DW, Amos AJ (1957) 'Modern cereal chemistry.' 5th edn. (Northern Publishing Co. Ltd: Liverpool)

Kirby RM, Jones FM, Ferguson DM, Fisher AD (2004) Adaptation to grain feeding. In 'Feeding grain for sheep meat production'. (Ed. HM Chapman) pp. 81-97. (Chief Executive Officer of the Australian Sheep Industry CRC: Bentley)
McCleary BV, Gibson TS, Solah V (1992) A rapid procedure for total starch measurement in cereal grains and products. In 'Proceedings of the 42nd RACI cereal chemistry conference. Christchurch, New Zealand, 7-11 September, 1992'. pp. 304-312.

Meat and Livestock Australia (2005) 'Fast facts: Australia's sheepmeat industry.' Available at http://www.mla.com.au/NR/rdonlyres/ 51787F9C-9D3E-4FB2-A 610-8CB5D17E0CC6/0/Sheep FastFacts04.pdf [Verified 4 August 2007]

Purchas RW, Aungsupakorn R (1993) Further investigations in the relationship between ultimate $\mathrm{pH}$ and tenderness for beef samples from bulls and steers. Meat Science 34, 163-178. doi:10.1016/03091740(93)90025-D

Rooney LW, Pflugfelder RL (1986) Factors affecting starch digestibility with special emphasis on sorghum and corn. Journal of Animal Science 63, 1607-1623.

Saba H, Hale W, Hubbert F, Kiernat J, Taylor B (1964) Digestion of milo and barley by cattle. Journal of Animal Science 23, 533-536.

Silano V (1977) Factors affecting the digestibility and availability of proteins in cereals. In 'Nutritional evaluation of cereal mutants. Proceedings of the advisory group meeting on nutritional evaluation of cereal mutants. International Atomic Agency, Vienna'. pp. 13-46.

Sweeney RA (1989) Generic combustion method for determination of crude protein in feeds. Journal of the Association of Official Analytical Chemists 72, 770-774.

Theurer CB, Huber JT, Delgado-Elorduy A, Wanderley R (1999) Invited review: summary of steam-flaking corn or sorghum grain for lactating dairy cows. Journal of Dairy Science 82, 1950-1959.

Wiese SC, White CL, Masters DG, Milton JTB, Davidson RH (2003) Growth and carcass characteristics of prime lambs fed diets containing urea, lupins or canola meal as a crude protein source. Australian Journal of Experimental Agriculture 43, 1193-1197. doi:10.1071/EA02134

White A, Shands C, Casburn G (2001) 'Making the most of mutton.' (Ed. G Murray) (The State of New South Wales, NSW Agriculture and Meat and Livestock Australia: Sydney)

Wythes JR, Ramsay WR (1981) Beef carcass composition and meat quality. Information Series QI83002. Queensland Department of Primary Industries, Brisbane.

Manuscript received 26 April 2006, accepted 15 March 2007 